05.04.2007 p. No. 167. Ukrainian. Available from: http://mozdocs.kiev.ua/view.php?id=6958

3. [The European Committee on Antimicrobial Susceptibility Testing. Routine and extended internal quality control as recommended by EUCAST. Version 8.0, 2018]. Russian. Available from: http://www.eucast.org

4. Biesiedin OM, Kosulnykov SO, Storubel LM, et al. [Infections caused by isolates of Pseudomonas aeruginosa in patients with septic surgery]. Suchasni medychni tekhnolohii. 2019;2(41 Pt 1):56-60. Ukrainian. doi https://doi.org/10.34287/MMT.2(41).2019.11

5. [Antimicrobial resistance prevention and control: The European Commission has conducted a workshop]. Ukrainian. Available from: https://www.apteka.ua/article/505850

6. [On the implementation of the order of the Ministry of Health of Ukraine of April 05, 2007 No. 167 "On approval of methodological guidelines "Determination of sensitivity of microorganisms to antibacterial drugs" in 2017"]. Informatsiinyi biuleten DU «UISD MOZ Ukraïni». Kyiv; 2018:5. Ukrainian.

7. [On the organization of control and prevention of postoperative purulent-inflammatory infections caused by microorganisms resistant to the action of antimicrobials]. Nakaz MOZ Ukraïni. 04.04.2012 p. No. 236. Ukrainian. Available from:

https://zakon.rada.gov.ua/laws/show/z0912-12/stru

8. Central Asian and Eastern European Surveillance of Antimicrobial Resistance. Annual report 2018. Available from: http://www.euro.who.int/en/health-topics/disease-prevention/antimicrobial-resistance/publications/2018/central-asian-and-eastern-european-surveillance-ofantimicrobial-resistance-annual-report-2018-2018

9. Implementation of the global action plan on antimicrobial resistance. Newsletter WHO GAP AMR. 2017;32. Available from: https://www.who.int/antimicrobial-resistance/news/WHO-GAP-AMR-Newsletter-No32-Nov-2017.pdf?ua=1

10. Tackling Drug-Resistant Infections Globally: Final Report and Recommendations. The Review on Antimicrobial Resistance chaired by Jim O’Neill. May, 2016:81. Available from: https://amr-review.org/sites/default/files/160518_Final\%20paper_with\%20cover.pdf

Стаття надійшла до редакції 25.10.2019

\section{С.І. Саволюк,}

В.М. Лисенко,

М.Ю. Крестянов, Д.С. Завертиленко, С.К. Круаляк

\section{ПІСЛЯОПЕРАЦІЙНИЙ РЕФЛЮКС-ЕЗОФАГІТ ЯК ПРЕДИКТОР ВИБОРУ РЕСТРИКТИВНОЇ ОПЕРАЦІЇ У ХВОРИХ НА МЕТАБОЛІЧНИЙ СИНДРОМ}

Національна медична академія післядипломної освіти ім. П.Л. Шупика кафедра хірургії та судинної хірургії вул. Дрогожсииька, 9, Київ, 04112, Украӥна Shupyk National medical academy of postgraduate education Department of Surgery and Vascular Surgery Dorohozhytska str., 9, Kyiv, 04112, Ukraine e-mail: savoluk@meta.ua

Цитування: Медичні перспективи. 2020. Т. 25, № 1. С. 127-133

Cited: Medicni perspektivi. 2020;25(1):127-133

Ключові слова: ожиріння, метаболічний синдром, рукавна резекція, гастроплікація, фундоплікація, лапароскопія, гастроезофагальна рефлюксна хвороба, рефлюкс-езофагіт

Ключевые слова: ожирение, метаболический синдром, рукавная резекция, гастропликаџия, фундопликаџия, лапароскопия, гастроезофагальная рефлюксная болезнь, рефлюкс-езофагит

Key words: obesity, metabolic syndrome, sleeve gastrectomy, gastroplication, fundoplication, laparoscopy, gastroesophageal reflux disease, reflux esophagitis 
Реферат. Послеоперационный рефлюкс-эзофагит как предиктор выбора вида рестриктивной операции у пациентов с метаболическим синдромом. Саволюк С.И., Лысенко В.Н., Крестьянов Н.Е., Завертыленко Д.С., Кругляк Е.К. Цель данного исследования заключалась в проведении сравнительного анализа ретроспективных результатов лапароскопической рукавной резекции желудка (ЛРРШ), лапароскопической гастропликации (ЛГП) и лапароскопической фундогастропликаџии (ЛФГП) (симультанное выполнение фундопликации по Nissen u гастропликачии), полученных в срок наблюдения 1 год, с целью оченить и сравнить эффективность предупреждения краткосрочных послеоперационных осложнений, которые проявляются в виде ГЭРБ, путем выполнения превентивной антирефлюксной процедуры в сочетании с рестиктивной бариатрической операцией. Оценка эффективности и отдаленных последствий представленных рестриктивных операций проводилась на основе ретроспективных данных, полученных во время курации 46 больных ожирением и

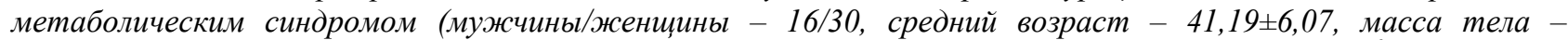

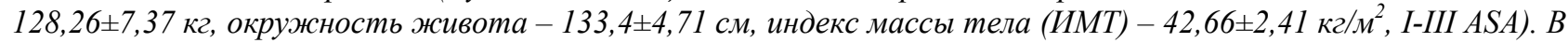
дооперачионном и послеоперационном периодах во время консультаций всем пациентам в обязательном порядке проводились измерения антропометрических показателей, контроль лабораторных данных $u$ результатов инструментальных методов исследования. Все представленные метаболические процедуры были выполнены на базах кафедры хирургии и сосудистой хирургии НМАПО им. П.Л. Шупика в период с 2016 . по 20192. 13 пациентам была проведена ЛРРЖ, 20 - ЛГП и 13 - ЛФГП. Повторные консультаџии с изелью контроля результатов проводились на 1, 3, 6 и 12 месяиах послеоперационного периода. Средний показатель

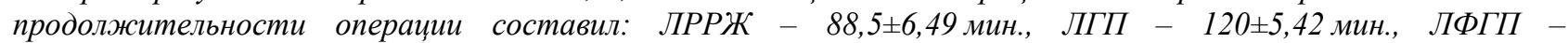

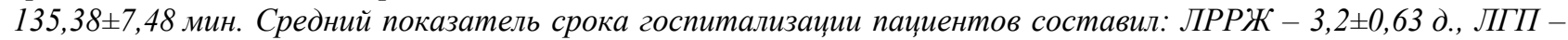

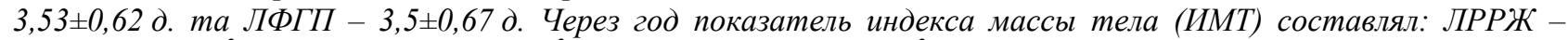

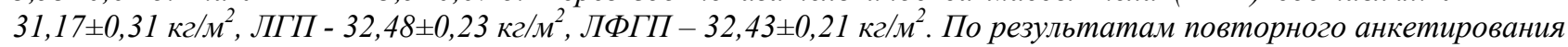
паџиентов через год после проведенной операции у 3 (23,07\%) из группь ЛРРЖ и 5 (25,0\%) из группь ЛГП имели место проявления симптомов ГЭРБ, которые не удавалось устранить с помошью консервативной терапии, что значительно ухудшало качество жизни пациентов. В группе пациентов, которым проводилась ЛФГП, данное осложнение отсутствовало. После проведения контрольной ФЭГДС через 1 год были обнаружены dе поvо признаки рефлюкс-эзофагита (согласно классификации Лос-Анджелес 1998 г.): в группе ЛРРЖ - 3 (23,07\%) паџиента (2 - степень А и 1 - степень В), в группе ЛГП - 5 (25,0\%) пациентов (3 - степень А и 2 - степень В). Среди паџиентов, которым была проведена ЛФГП, признаков рефлюкс-эзофагита не было обнаружено. Учитывая возможное развитие ГЭРБ и рефлюкс-эзофагита через год после проведенной рестриктивной операции, является актуальньмм применение превентивных мероприятий, заключающихся в одномоментном выполнении антирефлюксной и метаболической операций, что в данном исследовании демонстрируется на примере ЛФГП. Мы рекомендуем отдавать предпочтение проведению именно симультанных операций для достижения не только высоких показателей снижения веса, но и улучшения качества жизни пациентов в дальнейшем.

Abstract. Post-operative reflux esophagitis as a predictor of choice of restrictive operation in patients with metabolic syndrome. Savoliuk S.I., Lysenko V.M., Krestianov M.Y., Zavertylenko D.S., Krugliak Y.K. The purpose of this study was to conduct a comparative analysis of the retrospective results of laparoscopic sleeve gastrectomy (LSG), laparoscopic gastroplication (LGP) and laparoscopic fundogastroplication (LFGP) (simultaneous performance of fundoplication by Nissen and gastroplication) obtained at the follow-up period of 1 year, to evaluate and compare the effectiveness of prevention of short-term postoperative complications, which are manifested in the form of GERD, by performing preventive antireflux procedure in combination with restrictive bariatric surgery. Evaluation of the effectiveness and long-term effects of the presented restrictive operations was carried out on the basis of retrospective data obtained during the supervision of 46 patients with obesity and metabolic syndrome (men / women - 16/30, average age - 41.19 6.07 , body weight - $128.26 \pm 7.37 \mathrm{~kg}$, abdominal circumference - $133.4 \pm 4.71 \mathrm{~cm}$, body mass index (BMI) $-42.66 \pm 2.41 \mathrm{~kg} / \mathrm{m}^{2}$, I-III ASA). In the preoperative and postoperative periods, during consultations, in all patients measurements of anthropometric indicators were performed, laboratory data and results of instrumental research were considered. All metabolic procedures presented were performed at the basis of the Department of Surgery and Vascular Surgery of NMAPE named after P.L. Shupik in the period from 2016 to 2019.13 patients underwent LSG, 20 - LGP and 13 - LFGP. In order to control the results, repeated consultations were carried out at 1 , 3, 6 and 12 months of the postoperative period. The average duration of the operation was: $L S G-88.5 \pm 6.49 \mathrm{~min}, L G P$

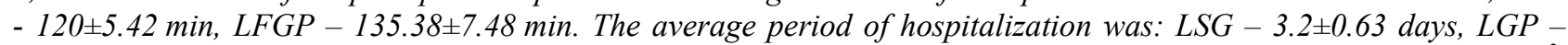
$3.53 \pm 0.62$ days, and LFGP - 3.5 \pm 0.67 days. After a year, the body mass index (BMI) was: $L S G-31.17 \pm 0.31 \mathrm{~kg} / \mathrm{m}^{2}$, $L G P-32.48 \pm 0.23 \mathrm{~kg} / \mathrm{m}^{2}, L F G P-32.43 \pm 0.21 \mathrm{~kg} / \mathrm{m}^{2}$. According to the results of a repeated questioning of patients one year after the operation, 3 (23.07\%) of the LSG group and 5 (25.0\%) of the LGP group had symptoms of GERD, which failed to be eliminated with the help of conservative therapy, life quality of patients became significantly worse. In the group of patients who underwent LFGP, this complication was absent. After the control gastroscopy, 1 year after, de novo signs of reflux esophagitis were detected (according to the Los Angeles classification): in the LSG group - 3 (23.07\%) patients (2 - grade A and 1 - grade B), in the LGP group - 5 (25.0\%) patients (3 - grade A and 2 - grade B). 
Among patients who underwent LFGP, there were no signs of reflux esophagitis. Considering the possible development of GERD and reflux esophagitis in one year after the restrictive surgery, the use of preventive measures consisting in the simultaneous performance of antireflux and metabolic operations is relevant, this is demonstrated by the example of LFGP. We recommend to give preference to simultaneous operations for the achievement of not only high rates of weight loss, but also for improvement of the quality of patients`life in the future.

Однією 3 найбільш актуальних проблем сучасного суспільства усіх країн світу $є$ підвищення рівня захворюваності на ожиріння та метаболічний синдром, що також є ключовим фактором розвитку супутніх захворювань, таких як цукровий діабет [15], серцево-судинні захворювання [5], деякі типи раку [4], різні види опорно-рухових розладів [16], порушення психічно-емоціонального аспекту здоров'я [1], що в комбінації значно знижують працездатність, якість та термін життя і підвищують витрати у сфері охорони здоров'я для лікування хворих на цю патологію. За останніми даними, з 1980 р. по 2015 р. загальна кількість осіб $з$ надлишковою вагою та хворих на ожиріння збільшилась у 2 рази, що становить $1 / 3$ дорослого населення світу [9]. Відповідно до цієї негативної тенденції прогнозується, що в 2030 р. рівень осіб $з$ надлишковою вагою та ожирінням буде становити 57,8\% населення світу [10]. Серед усіх можливих методів лікування провідне місце посідає баріатрична хірургія як безпечний та ефективний спосіб боротьби 3 ожирінням i супутніми захворюваннями, асоційованими 3 ним. Ураховуючи інтенсивне зростання питомої ваги захворюваності на цю патологію, має місце прямопропорційне підвищення кількості проведених метаболічних процедур, питома вага яких зростає щороку. За даними четвертого IFSO Global Registry Report 2018 р., загальна кількість баріатричних операцій становила 394,431, що у 2 рази перевищує показники минулого року. Переважаючу кількість серед них становлять рестриктивні операції, а найбільш поширеною метаболічною процедурою цього типу була рукавна резекція шлунка, питома частка якої становила 45,9\% від загальної кількості [3]. Однак за різними даними $[2,8,11,14]$ існує проблема розвитку de novo або обтяження симптомів гастроезофагальної рефлюксної хвороби (ГЕРХ) та рефлюкс-езофагіту в пацієнтів після проведеної рукавної резекції в короткостроковому періоді, що відповідно погіршувало якість життя пацієнтів. Це робить актуальним подальше дослідження та пошук превентивних методів та способів усунення такого віддаленого ускладнення.

Мета цього дослідження полягала в проведенні порівняльного аналізу ретроспективних результатів ефективності та віддалених наслідків лапароскопічної рукавної резекції шлунка (ЛРРШ), лапароскопічної гастроплікації (ЛГП) та лапароскопічної фундогастроплікації (симультанне виконання фундоплікації за Nissen та гастроплікації) (ЛФГП), отриманих у термін спостереження 1 рік, що має на меті оцінити та порівняти ефективність попередження короткострокових післяопераційних ускладнень, які проявляються у вигляді ГЕРХ, шляхом виконання превентивної антирефлюксної процедури в поєднанні з рестриктивною баріатричною операцією.

\section{МАТЕРІАЛИ ТА МЕТОДИ ДОСЛІДЖЕНЬ}

Порівняльна оцінка ефективності та віддалених наслідків представлених рестриктивних операцій проводилась на основі ретроспективних даних, отриманих під час курації 46 хворих на ожиріння та метаболічний синдром (чолові-

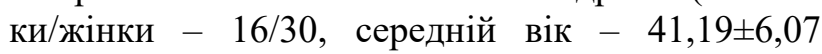
$(\mathrm{p}=0,999)$, маса тіла $-128,26 \pm 7,37$ кг $(\mathrm{p}=0,999)$,

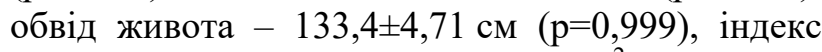
маси тіла (IMT) - 42,66 $\pm 2,41 \mathrm{\kappa г} / \mathrm{m}^{2}$, I-III ASA $(p=0,999))$. У доопераційному періоді всім пацієнтам була проведена консультація, під час якої надавались передопераційні рекомендації (кожному пацієнту видавалась пам'ятка 3 переліком рекомендацій з підготовки до хірургічного лікування, яких пацієнти чітко дотримувались комплаєнсу досягнуто), інформація про доступні варіанти метаболічних процедур та можливі короткострокові і довгострокові результати (очікувана втрата ваги; відомі максимальні терміни спостереження для досягнення результату; можливий повторний набір ваги; негативні ефекти, які можуть мати вплив на якість життя, такі як утворення додаткових шкірних складок, необхідність прийому ліків, зміна харчової поведінки тощо) та наявність альтернативних не хірургічних методів лікування ожиріння та їх результативність порівняно 3 баріатричними операціями. Інформовану згоду на проведення хірургічного лікування отримано [13]. У доопераційному та післяопераційному періодах під час консультацій усім пацієнтам в обов'язковому порядку проводились вимірювання антропометричних показників, контроль лабораторних даних (загальний аналіз крові, загальний аналіз сечі, біохімічний аналіз крові, глікований гемоглобін, індекс НОМА, рівень тригліцеридів, ліпопротеїди низької та дуже низької щільності) 
та результатів інструментальних методів дослідження (УЗД органів черевної порожнини, ФЕГДС, рентгеноскопію 3 контрастуванням верхніх відділів шлунково-кишкового тракту) 3 метою виявлення супутніх захворювань та післяопераційних ускладнень [7]. За результатами досліджень були виявлені такі супутні захворювання: артеріальна гіпертензія (28 пацієнтів), дисліпідемія (24 пацієнти), ЦД II типу (8 пацієнтів). Якість життя пацієнтів відповідно до проявів сиптомів ГЕРХ оцінювалась за допомогою анкети GERD Q (табл. 1). Критерієм вилучення пацієнтів 3 цього дослідження була наявність симптомів гастроезофагальної рефлюк- сної хвороби (ГЕРХ), грижі стравохідного отвору діафрагми (ГСОД) та рефлюкс-езофагіту - за результатами досліджень вищевказані захворювання були відсутні в усіх пацієнтів у доопераційному періоді. Усі представлені метаболічні процедури були виконані на базах кафедри хірургії та судинної хірургії НМАПО ім. П.Л. Шупика в період 32016 по 2019 р. 3 них 13 пацієнтам була проведена ЛРРШ, 20 - ЛГП та 13 - ЛФГП. Період спостереження пацієнтів після хірургічного лікування становив 1 рік. Повторні консультаціі 3 метою контролю результатів проводились на 1, 3, 6 та 12 місяцях післяопераційного періоду.

Таблиця 1

Показники зниження ваги протягом 1 року $(\mathrm{M} \pm \mathrm{m})$

\begin{tabular}{l|c|c|c|c}
\hline \multicolumn{1}{c|}{ Групи паціснтів } & 1 міс. & 3 міс. & 6 міс. & 12 міс. \\
\hline ЛРРШ & $38,46 \pm 0,45$ & $36,10 \pm 0,36$ & $33,45 \pm 0,41$ & $31,17 \pm 0,31$ \\
ЛГП & $38,86 \pm 0,36$ & $36,69 \pm 0,29$ & $34,57 \pm 0,24$ & $32,48 \pm 0,23$ \\
ЛФГП & $38,81 \pm 0,29$ & $36,76 \pm 0,18$ & $34,49 \pm 0,29$ & $32,43 \pm 0,21$ \\
\hline
\end{tabular}

\section{РЕЗУЛЬТАТИ ТА ЇХ ОБГОВОРЕННЯ}

Середній показник тривалості операції ста-

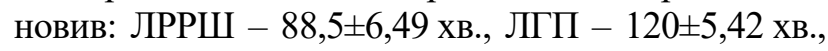
ЛФГП - $135,38 \pm 7,48$ хв. $(\mathrm{p}=0,999) \quad$ [11]. ранньому післяопераційному періоді у 3 $(23,07 \%)$ з групи ЛРРШ та 4 (20,0\%) пацієнтів 3 групи ЛГП відмічалась транзиторна блювота, прояви якої на фоні консервативної терапії зникали через добу. Для пацієнтів з групи ЛФГП відповідних ускладнень не відмічалось.
Середній показник терміну госпіталізації

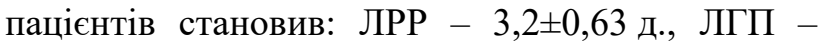

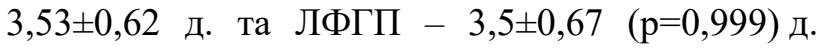
$(\mathrm{p}=0,999)[11]$.

Через рік після проведення хірургічного лікування хворих на ожиріння та 3 метаболічним синдромом було досягнуто таким результатів: IMT для пацієнтів після ЛРРШ становив $31,17 \pm 0,31 \mathrm{\kappa} / \mathrm{m}^{2}$, ЛГП - 32,48 $\pm 0,23 \mathrm{\kappa} / \mathrm{m}^{2}$, ЛФГП $32,43 \pm 0,21 \kappa \Gamma / \mathrm{m}^{2}$ (p=0,999) (рис.) [12].

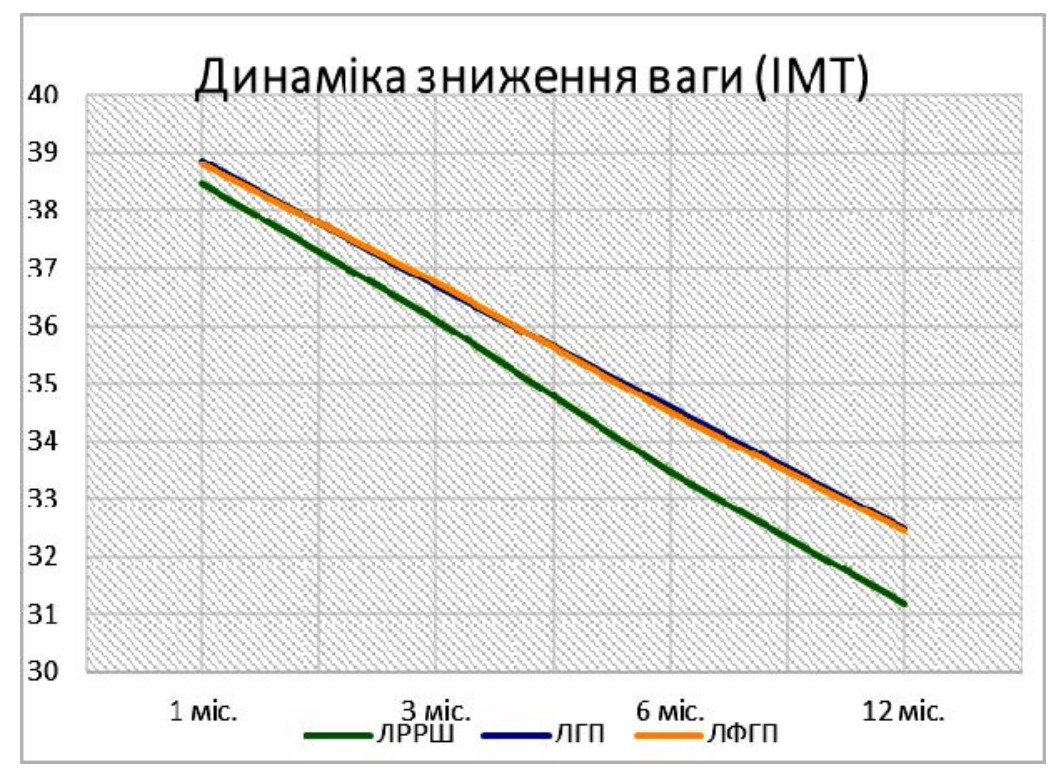

Графік динаміки зниження ваги паціснтів 
Під час проведення цього дослідження відмічалась компенсація цукрового діабету II типу - у 6 (75,0\%) осіб, артеріальної гіпертензії у $22(78,5 \%)$ осіб та нормалізація ліпідного профілю - у 19 (79,16\%) осіб.

Під час проведення опитування пацієнтів відповідно до анкети GERD Q у доопераційному періоді прояви ГЕРХ були відсутні в пацієнтів усіх трьох груп (середнє значення - 3,8 бала). За результатами повторного анкетування пацієнтів через рік після проведеної операції у $3(23,07 \%) 3$ групи ЛРРШ та $5(25,0 \%)$ г групи ЛГП мали місце прояви симптомів ГЕРХ (середнє значення для ЛРРШ - 9,5, ЛГП - 9,4) (табл. 2), які потребували застосування консервативної терапіi, що погіршувало якість життя пацієнтів. У групі пацієнтів, котрим проводилась ЛФГП, таке ускладнення було відсутнє.

Таблиця 2

\section{Результати анкетування паціснтів через рік після проведеної операції}

\begin{tabular}{|c|c|c|c|}
\hline Групи паціснтів & Загальна кількість пацієнтів & \multicolumn{2}{|c|}{ Симптоми ГЕРХ de novo через рік } \\
\hline ЛРРШ & 13 & 3 & $23,07 \%$ \\
\hline ЛГП & 20 & 5 & $25,00 \%$ \\
\hline ЛФГП & 13 & 0 & $0,00 \%$ \\
\hline
\end{tabular}

Після проведення контрольної ФЕГДС через 1 рік були виявлені de novo ознаки рефлюксезофагіту (відповідно до класифікації ЛосАнджелес): у групі ЛРР - 3 (23,07\%) пацієнти (2 - ступінь А та 1 - ступінь В), у групі ЛГП - 5 (25\%) пацієнтів (3 - ступінь А та 2 - ступінь В). Серед пацієнтів, котрим була проведена ЛФГП, ознак рефлюк-езофагіту не було виявлено.

Через рік у 3 пацієнтів після ЛРР та у 5 після ЛГП при контрольній рентгеноскопії 3 контрастуванням розчином барію були зафіксовані епізоди гастро-езофагального рефлюксу контрасту та помірне розширення проксимальних відділів шлунка, порівняно 3 пацієнтами групи ЛФГП.

Ураховуючи значний приріст питомої ваги пацієнтів, котрі страждають на ожиріння та метаболічний синдром, спостерігається зростання загальної кількості проведених баріатричних операцій, які представляють собою найбільш ефективний метод лікування цього захворювання. Найбільшу частку серед усіх представлених баріатричних процедур становить рукавна резекція шлунка, що є представником метаболічних процедур рестриктивного типу, які проявляють свою ефективність щодо зниження ваги та досягнення ремісії супутніх захворювань, викликаних ожирінням, що значно покращує якість життя пацієнтів. Гастроплікація - баріатрична операція рестриктивного типу, яка має результативність, подібну після проведеної рукавної гастректомії, без резекції великої кривини шлунка, але ця операція залишається мало вивченою. За даними різних джерел, в яких повідомляється про можливий розвиток ускладнення у вигляді виникнення de novo проявів сиптомів ГЕРХ і ознак рефлюкс-езофагіту в короткостроковому та довгостроковому періодах [13], вважається за необхідне застосування консервативної тарапії, що призводить до зниження якості життя пацієнтів після проведеної метаболічної процедури. При неефективності медикаментозної терапії в подальшому $\epsilon$ необхідним проведення повторного хірургічного втручання 3 метою корекції такого патологічного стану. Ця проблема робить актуальним використання, що в цьому дослідженні демонструється на прикладі одномоментного виконання лапароскопічної гастроплікації та фундоплікації за Nissen, та пошук нових превентивних заходів під час реалізації метаболічної процедури, маючи на меті не лише лікування ожиріння та метаболічного синдрому, а й попередження віддалених наслідків його хірургічного лікування 3 подальшим дослідженням результатів у догостроковому періоді при виконанні цього виду симультанних операцій.

\section{ПІДСУМОК}

Ураховуючи можливий розвиток ГЕРХ та рефлюкс-езофагіту через рік після проведеної рестриктивної операції, $€$ актуальним застосування превентивних заходів, що полягають в одномоментному виконанні антирефлюксної та метаболічної операцій, що в цьому дослідженні демонструється на прикладі ЛФГП. Така процедура показує свою ефективність не лише щодо 
до зниження маси тіла, досягнення ремісії та контролю супутніх захворювань, а й у попередженні віддалених ускладнень після проведення рестриктивної метаболічної процедури, що у свою чергу дозволяє запобігти застосуванню медикаментозної терапії, яка знижує якість життя пацієнтів, та дозволяє уникнути можливого повторного хірургічного втручання 3 метою лікування ГЕРХ та рефлюкс-езофагіту, викликаних метаболічною процедурою. Однак цей вид хірургічного лікування потребує подальшого ретроспективного дослідження. Відповідно до цього ми рекомендуємо надавати перевагу проведенню саме симультанних операцій для досягнення не лише високих показників зниження ваги, а й покращення якості життя пацієнтів в подальшому.

Тема ініціативно-пошукової НДР кафедри хірургії та судинної хірургї НМАПО імені П.Л. Шупика: "Інновачійні технологї в хірургічному лікуванні захворювань органів черевної порожнини, черевної стінки та судин».

Термін виконання: 01.2017-10.2021 рр., № державної реєстрації: $0117 U 002468$.

\section{СПИСОК ЛІТЕРАТУРИ}

1. Anstey K. J., Cherbuin N., Budge M., Young J. (2011). Body mass index in midlife and late-life as a risk factor for dementia: a meta-analysis of prospective studies. Obesity Reviews, 2011, Vol. 12, No. 5. e426-e437. DOI: https://doi.org/10.1111/j.1467-789X.2010.00825.x

2. Association between gastroesophageal reflux disease and laparoscopic sleeve gastrectomy / P. R. Carter, et al. Surgery for Obesity and Related Diseases, 2011. Vol. 7, No. 5. P. 569-572.

DOI: https://doi.org/10.1016/j.soard.2011.01.040

3. Bariatric Surgery Worldwide: Baseline Demographic Description and One-Year Outcomes from the Fourth IFSO Global Registry Report 2018 / R. Welbourn, et al. Obesity Surgery.

DOI: https://doi.org/10.1007/s11695-018-3593-1

4. Body Fatness and Cancer - Viewpoint of the IARC Working Group / B. Lauby-Secretan, et al. New England Journal of Medicine. 2016. Vol. 375, No. 8. P. 794-798.

DOI: https://doi.org/10.1056/NEJMsr1606602

5. Body mass index, waist circumference and waisthip ratio: which is the better discriminator of cardiovascular disease mortality risk? Evidence from an individual-participant meta-analysis of 82864 participants from nine cohort studies / S. Czernichow et al. Obesity Reviews. 2011. Vol. 12, No.9. P. 680-687. DOI: https://doi.org/10.1111/j.1467-789X.2011.00879.x

6. Enhanced Recovery after Bariatric Surgery: Systematic Review and Meta-Analysis / Piotr Małczak, et al. OBES SURG. 2017. Vol.27. P. 226-235 DOI: https://doi.org/10.1007/s11695-016-2438-z

7. European Guidelines for Obesity Management in Adults / Volkan Yumuk, et al. Obes Facts. 2015. Vol. 8. P. 402-24. DOI: https://doi.org/10.1159/000442721

8. Gastroesophageal Reflux Disease After Sleeve Gastrectomy / I. Braghetto, et al. Surgical Laparoscopy,
Endoscopy \& Percutaneous Techniques. 2010. Vol. 20, No. 3. P. 148-53.

DOI: https://doi.org/10.1097/SLE.0b013e3181e354bc

9. Global Burden of Disease Collaborative Network. Global Burden of Disease Study 2015 (GBD 2015) Obesity and Overweight Prevalence 1980-2015. Seattle, United States: Institute for Health Metrics and Evaluation (IHME), 2017.

10. Global burden of obesity in 2005 and projections to 2030 / T. Kelly et al. Inter. Journal of Obesity. 2008. Vol. 32, No. 9. P. 1431-1437.

DOI: https://doi.org/10.1038/ijo.2008.102

11. Himpens J., Dobbeleir J., Peeters G. Long-term results of laparoscopic sleeve gastrectomy for obesity. Ann Surg. 2010. Vol. 252. P. 319-24. PMID: 20622654. DOI: https://doi.org/10.1097/SLA.0b013e3181e90b31

12. Jennifer Peat, Belinda Barton. Medical Statistics: A Guide to Data Analysis and Critical Appraisal. 2005. DOI: https://doi.org/10.1002/9780470755945

13. Laparoscopic sleeve gastrectomy for obesity: can it be considered a definitive procedure? / A. Chopra, et al. Surgical Endoscopy. 2011. Vol. 26, No. 3. P. 831-7. DOI: https://doi.org/10.1007/s00464-011-1960-2

14. Mid-term Follow-up after Sleeve Gastrectomy as a Final Approach for Morbid Obesity / E. Arias, et al. Obesity Surgery, 2009. Vol. 19, No. 5. P. 544-8. DOI: https://doi.org/10.1007/s11695-009-9818-6

15. The Age-Specific Quantitative Effects of Metabolic Risk Factors on Cardiovascular Diseases and Diabetes: A Pooled Analysis / G. M. Singh, et al. PloS ONE. 2013. Vol. 8, No. 7. P. e65174. DOI: https://doi.org/10.1371/journal.pone.0065174

16. The impact of obesity on the musculoskeletal system / A. Anandacoomarasamy, et al. Inter. Journal of Obesity. 2007. Vol. 32, No. 2. P. 211-22. DOI: https://doi.org/10.1038/sj.ijo.0803715

\section{REFERENCES}

1. Anstey KJ, Cherbuin N, Budge M, Young J. (2011). Body mass index in midlife and late-life as a risk factor for dementia: a meta-analysis of prospective studies. Obesity Reviews, 12(5), e426-e437. doi: https://doi.org/10.1111/j.1467-789X.2010.00825.X 
2. Carter PR, LeBlanc KA, Hausmann MG, Kleinpeter KP, deBarros SN, Jones SM. Association between gastroesophageal reflux disease and laparoscopic sleeve gastrectomy. Surgery for Obesity and Related Diseases. 2011;7(5):569-572.

doi: https://doi.org/10.1016/j.soard.2011.01.040

3. Welbourn R, Hollyman M, Kinsman R, Dixon J, Liem R, Ottosson J, Himpens J. Bariatric Surgery Worldwide: Baseline Demographic Description and One-Year Outcomes from the Fourth IFSO Global Registry Report 2018. Obesity Surgery.

doi: https://doi.org/10.1007/s11695-018-3593-1

4. Lauby-Secretan B, Scoccianti C, Loomis D, Grosse Y, Bianchini F, Straif K. Body Fatness and Cancer Viewpoint of the IARC Working Group. New England Journal of Medicine. 2016;375(8):794-798. doi: https://doi.org/10.1056/NEJMsr1606602

5. Czernichow S, Kengne A-P, Stamatakis E, Hamer M, Batty GD. Body mass index, waist circumference and waist-hip ratio: which is the better discriminator of cardiovascular disease mortality risk? Evidence from an individual-participant meta-analysis of 82864 participants from nine cohort studies. Obesity Reviews. 2011;12(9):680-7

doi: https://doi.org/10.1111/j.1467-789X.2011.00879.x

6. Piotr Małczak, Magdalena Pisarska, Major Piotr, Michał Wysocki, Andrzej Budzyński, and Michał Pędziwiatr. Enhanced Recovery after Bariatric Surgery: Systematic Review and Meta-Analysis. OBES SURG. 2017;27:226-235.

doi: https://doi.org/10.1007/s11695-016-2438-z

7. Volkan Yumuk, Constantine Tsigos, Martin Fried et al.. European Guidelines for Obesity Management in Adults. Obes Facts. 2015;8:402-424. doi: https://doi.org/10.1159/000442721

8. Braghetto I, Csendes A, Korn O, Valladares H, Gonzalez P, Henríquez A. Gastroesophageal Reflux Disease After Sleeve Gastrectomy. Surgical Laparoscopy,
Endoscopy \& Percutaneous Techniques. 2010;20(3):148153. doi: https://doi.org/10.1097/SLE.0b013e3181e354bc

9. Global Burden of Disease Collaborative Network. Global Burden of Disease Study 2015 (GBD 2015) Obesity and Overweight Prevalence 1980-2015. Seattle, United States: Institute for Health Metrics and Evaluation; 2017.

10. Kelly T, Yang W, Chen C-S, Reynolds K, He J. Global burden of obesity in 2005 and projections to 2030 . International Journal of Obesity. 2008;32(9):1431-7. doi: https://doi.org/10.1038/ijo.2008.102

11. Himpens J, Dobbeleir J, Peeters G. Long-term results of laparoscopic sleeve gastrectomy for obesity. Ann Surg. 2010;252:319-324 PMID: 20622654 doi: https://doi.org/10.1097/SLA.0b013e3181e90b31

12. Jennifer Peat, Belinda Barton. Medical Statistics: A Guide to Data Analysis and Critical Appraisal; 2005. doi: https://doi.org/10.1002/9780470755945

13. Chopra A, Chao E, Etkin Y, Merklinger L, Lieb J, Delany H. Laparoscopic sleeve gastrectomy for obesity: can it be considered a definitive procedure? Surgical Endoscopy. 2011;26(3):831-837.

doi: https://doi.org/10.1007/s00464-011-1960-2

14. Arias E, Martínez PR, Ka Ming, Li V, Szomstein S, Rosenthal RJ. Mid-term Follow-up after Sleeve Gastrectomy as a Final Approach for Morbid Obesity. Obesity Surgery. 2009;19(5):544-8. doi: https://doi.org/10.1007/s11695-009-9818-6

15. Singh GM, Danaei G, Farzadfar F, Stevens GA, Woodward M, Wormser D. The Age-Specific Quantitative Effects of Metabolic Risk Factors on Cardiovascular Diseases and Diabetes: A Pooled Analysis. PLoS ONE. 2013;8(7):e65174.

doi: https://doi.org/10.1371/journal.pone.0065174

16. Anandacoomarasamy A, Caterson I, Sambrook P, Fransen M, March L. The impact of obesity on the musculoskeletal system. International Journal of Obesity, 2007;32(2):211-22.

doi: https://doi.org/10.1038/sj.ijo.0803715

Стаття надійшла до редакції 18.09.2019 